\title{
TURISMO E ETNICIDADE
}

\section{Rodrigo de Azeredo Grünewald Universidade Federal de Campina Grande - Brasil}

Resumo: Um dos aspectos mais significativos que marcam os estudos em antropologia do turismo é o da mudança cultural percebida em sociedades hospedeiras em conseqüência do impacto de um fluxo turístico. Muitas vezes essas mudanças são acompanhadas de uma reorganização da população hospedeira em linhas étnicas, ou seja, com o estabelecimento de etnicidades orientadas para o turismo. $O$ artigo pretende examinar as relações entre turismo e etnicidade em termos teóricos e tentar promover uma melhor compreensão do turismo étnico para o meio acadêmico.

Palavras-chave: comunidade turística, etnicidade, mudança cultural, turismo étnico.

Abstract: Cultural changes perceived in host societies as a result of tourism flow impact is one of the most significant aspects in Tourism Anthropology. Many times those changes are associated to some reorganization of the host population in ethnic terms, which is to say, with the setting up of tourism related ethnicities. The article aims at analyzing the theoretical relations between tourism and ethnicity, as well as to try and promote a better understanding of ethnic tourism in the Academia.

Keywords: cultural change, ethnic tourism, ethnicity, tourism community.

Turismo indica movimento de pessoas que não estão a trabalho em contextos diferentes do de origem, seja este o lar, a cidade ou o país. Tratase, geralmente, de visitação a lugares onde poderão ser desempenhadas as mais variadas formas de atividades práticas e/ou subjetivas desde que não o trabalho. A amplitude do termo parece caber desde ao olhar visitante a um monumento na própria cidade de origem até ao passeio em lugares totalmente desconhecidos de outros países. Se algumas definições de turismo destacam a prática ou a estrutura do fenômeno, acho que ambas as esferas - 
considerando suas dimensões simbólicas, subjetivas e até fenomenológicas devem caracterizar o fenômeno na medida em que as pessoas muitas vezes se sentem, ou não, em turismo.

Ainda que lazer e viagem possam ser considerados como "universais culturais" (Murdock et al., 1982) e fundamentos para uma definição básica de turismo, as origens deste têm merecido algumas investigações históricas. Se alguns autores procuram as origens do turismo na época da expansão colonial, outros as buscam nas peregrinações características dos séculos XVIII e XIX. Com certeza, pode-se afirmar somente que o turismo em larga escala emergiu no mundo ocidental no final do século XIX e início do XX. As origens do turismo são encontradas, além disso, em condições de alta produtividade, especialmente na sociedade industrial. Mas é com as transformações socioeconômicas experimentadas depois da II Guerra Mundial que o turismo se desenvolve como uma manifestação do consumo de massa (Pi-Sunyer, 1989, p. 191).

A amplitude e a relevância do turismo como fenômeno social é crescente desde então, não só pelos dados quantitativos que indicam uma movimentação entre países anual de mais de 600 milhões de pessoas (Banducci Jr.; Barretto, 2001) - além da movimentação de cerca de 450 bilhões de dólares só em 1998 (Grünewald, 2001) -, mas pelas suas inúmeras manifestações concretas esquematicamente já fixadas em diversas tipologias que tentaram estabelecer assuntos/objetos temáticos no âmbito desse amplo fenômeno.

Nas ciências sociais, os estudos sobre turismo começam a se fixar entre os anos 60 e $70^{1}$, quando aparece um número significativo de trabalhos sobre turismo, com relevo especial para a obra de Boorstin (1964), que destaca o aspecto do simulacro no âmbito da atividade turística. Em antropologia, é também na década de 60 que os trabalhos sobre turismo se iniciam - com destaque para o artigo de Nuñez, de 1963, sobre turismo de fim de semana em aldeia mexicana (Nash, 1996) -, mas ganham força e sistematicidade na década seguinte e principalmente com foco sobre pequenas comunidades e as interações sociais entre turistas e hospedeiros. Uma

${ }^{1}$ Embora o sociólgo Veblen tenha escrito trabalho em 1889 sobre lazer, classes sociais e consumo, tal objeto temático não obteve continuidade acadêmica na sociologia até o período que se inicia depois da II Guerra Mundial, mais propriamente na década de 1950, com as preocupações de Friedman sobre o lazer como alívio para o trabalho (Steil, 2002). 
multiplicidade de objetos começa a se colocar aos pesquisadores nos anos seguintes, e esses passam a ser tratados pelos mesmos métodos e teorias comuns à pesquisa antropológica em geral, tanto urbana quanto rural ou de grupos étnicos.

Assim, se turismo é um fenômeno muito complexo, não só por se apresentar quantitativamente com uma das maiores (se não a maior) indústrias do mundo, mas principalmente por uma enorme diversidade de objetivos programáticos, além dos aspectos subjetivos que perpassam todos os relacionamentos envolvidos nas suas múltiplas facetas, a antropologia do turismo não se apresenta como homogênea em sua abordagem, mas muito diversificada internamente na medida em que se constrói sob uma miríade de objetos temáticos. São estudos em turismo religioso, turismo e mudança social, turismo e mercantilização cultural, turismo e globalização, veraneio, turismo e lazer, ecoturismo, mediadores culturais na empresa turística, impactos sociais do turismo, turismo e produção de artesanato, turismo e etnicidade, entre outras rubricas. Além disso, turismo é uma área não só para atuação acadêmica dos antropólogos, mas de muita envergadura para o trabalho antropológico prático e aplicado ao turismo (Chambers, 1997; Nash, 1996), e principalmente em termos de desenvolvimento sustentável (Sofield, 2003).

Dentro de toda essa complexidade do fenômeno, gostaria de destacar um aparente paradoxo quanto à busca do objeto turístico pelos turistas. Hoje, no princípio do milênio em que se inicia o turismo espacial, há uma procura cada vez maior por sociedades em recônditos da Terra. Digo paradoxo aparente porque isso que se constrói como foco da visitação turística está na procura pelo diferente, pelo exótico, pelo outro que, na verdade, é buscado desde o início das jornadas turísticas. Perceber essa forma de experiência turística (Grünewald, 2001) caracterizada pela promoção do "outro" parece de extrema relevância para a antropologia (inclusive a aplicada) na medida, principalmente, em que isso tem se configurado tanto como alternativas econômicas valiosíssimas para as comunidades turísticas quanto para a própria revitalização cultural dessas populações em si, muitas vezes apresentando declínio indesejável de produção cultural em face dos problemas impostos pelo trabuco do capitalismo global - questão de "desenvolvimento cultural" que, segundo Ryan (2002), deve continuar sendo minuciosamente investigada em termos de sua autenticidade, na medida em que isso é importantíssimo para os próprios sujeitos nativos e turistas. 
Essa não é a mesma perspectiva que se insinuava no início da antropologia do turismo, quando as idéias de "impactos do turismo" e de "desenvolvimento turístico" começaram a receber atenção não só das ciências sociais e econômicas como também dos próprios agentes empreendedores que aplicam capital político, econômico e mesmo simbólico em certas sociedades. Mudanças ocorreram nestas e isso também se percebe pelo aspecto cultural e não meramente econômico. Muitas vezes essas mudanças foram pensadas em termos de uma aculturação em larga escala em face do impacto do turismo, isto é, o desenvolvimento turístico levaria os nativos de pequenas sociedades hospedeiras a abandonarem um modo de vida tradicional e independente do capitalismo global para se inserirem em negócios locais incrementados pelo "efeito multiplicador" (Smith, 1989) do desenvolvimento turístico.

Já outra perspectiva mais produtiva, que se inicia ainda na década de 1970, reforça a etnicidade promovida entre certas populações com um reforço de certas tradições (no caso das artes étnicas, ver Graburn, 1976a) que passaram à condição de chamariz turístico, e assim também participando da perspectiva do desenvolvimento local do turismo. Se o exótico, o outro, é procurado em lugares distintos do de origem do visitante, os habitantes desses lugares, de acordo com a perspectiva turística, devem se promover como esse exótico, a fim de ser atrativo no mercado turístico. Devem ter sinais diacríticos a exibir, a serem consumidos nesse amplo mercado. A construção, promoção ou fortalecimento de sinais diacríticos que caracterizam (que definem culturalmente) um povo é o próprio âmbito da etnicidade. Mas note-se que essa etnicidade não se refere estritamente à etnicidade clássica colonial, ou seja, não estou aqui me referindo só a grupos de nativos, mas a diversas formas de construção de fronteiras de grupos sociais que se fixam em linhas étnicas. Trata-se, conforme perspectiva de Hall (1991a, 1991b), não mais de etnicidades acionadas contra o imperialismo colonial, mas de "nova etnicidades" que, sem negar essa primeira forma de alinhamento, emergem de forma fragmentária, com segmentações internas e, em muitos casos, não conseguindo operar como totalidades. São movimentos localizados de emergência de novos sujeitos sociais, novas etnicidades, novas comunidades em posições subalternas que tentam falar de si mesmos contra o mundo anônimo e impessoal das forças globalizadas presentes na diversidade do mundo pós-moderno. A etnicidade, aí, seria o lugar ou o espaço necessário a partir do qual as pessoas falam. 


\section{Etnicidade e turismo}

Etnicidades são fenômenos sociais que refletem as tendências positivas de identificação e inclusão de certos indivíduos em um grupo étnico. A distintividade dessa identidade, para caracterizar um grupo étnico, deve se remeter a noções de origem, história, cultura e, até, raça comuns. Originalmente, destacaram-se duas perspectivas teóricas para se abordar e definir os grupos étnicos: uma essencialista, que se debruçava sobre a substância do patrimônio cultural e histórico das populações para perceber sua distintividade étnica, e outra, mais construtivista, que, focando as interações sociais entre as sociedades, notava suas fronteiras, que eram o que, efetivamente, definiria os limites do grupo étnico, independentemente se os traços de cultura ou raça fossem compartilhados com as sociedades vizinhas. Esta segunda tendência é a que recebeu maior notabilidade. Mas deve-se fazer uma ressalva ao dizer que, se a antropologia focaliza a interação social que cria as fronteiras étnicas, para os membros desses grupos o discurso étnico ressalta, na maioria dos casos, os conteúdos de sua origem, história, cultura ou raça - mesmo que esses sejam criados no presente para fins de autorepresentação ou de representação para os outros.

Assim, é importante destacar a instrumentalidade dos itens de cultura exibidos pelo grupo étnico como sinais diacríticos, ou seja, como suas marcas culturais (históricas, etc.) características e que os definem por oposição a outros grupos. É importante para os grupos étnicos portarem tais marcas e, quando não as possuem, muitas vezes as criam para fortalecer sua distintividade étnica. Geralmente, esses elementos de cultura são pensados (tratados) e operados como tradições - termo que indica substância constituinte de um povo, mas que, na prática, pode ser construída situacionalmente com vistas, inclusive, no futuro (Grünewald, 2001, 2002b).

Mas como a etnicidade se relaciona com o turismo? Ora, existem inúmeras formas de turismo e, embora algumas delas estejam totalmente despreocupadas com questões de história, cultura própria, raça, origem, como o turismo recreativo, outras formas tomam por objeto aspectos de identidade ou alteridade. No primeiro caso temos, por exemplo, o turismo histórico dentro da nossa própria sociedade, e, no segundo, a busca pelo exotismo ou simplesmente por outras culturas. Van den Berghe (1994) já sustentava que turismo é sempre uma forma de relações étnicas, e isso seria 
duplamente verdadeiro, segundo van den Berghe e Keyes (1984), no caso do chamado turismo étnico, onde a própria existência da fronteira étnica criaria a atração turística. Exploremos um pouco mais esse assunto que compõe o núcleo de nossa preocupação aqui.

\section{Turismo étnico}

Se uma das primeiras preocupações dos antropólogos com relação ao turismo foi porque tal atividade penetrava nas sociedades estudadas por eles e promovia mudanças (Nash, 1996, p. 20), essa presença começou cada vez mais a ser notada em relação às manifestações das identidades étnicas dessas populações. Acredito que Graburn (1976b) tenha sido pioneiro ao elaborar um conjunto de suposições sobre identidade e artes étnicas em relação com o turismo, em coletânea (Graburn, 1976a) que agrega vários estudos de casos dispostos regionalmente. Este autor percebia a etnicidade como uma construção identitária num mundo plural, onde comunicação, educação e viagem apareceriam como fundantes de conhecimento e de e acesso aos mais variados outros. Em tal cenário, "identidades ameaçadas" muitas vezes poderiam buscar uma renovação das tradições de um grupo, em apoio a um sentido de identidade única que, muitas vezes, pode unir as pessoas a um passado talvez mais glorioso que o presente. Mostra então que "arcaísmo" pode se configurar como uma variante de "compressão étnica", na tentativa deliberada de imitar ou mesmo reviver os estilos de um período anterior (passado recente ou remoto) de uma cultura própria "ou mesmo a ressurreição dos traços de alguma outra sociedade prestigiosa" (Graburn, 1976a, p. 25). Para ele, símbolos

de identidade podem ser emprestados, roubados ou mesmo trocados. Grupos podem desejar realçar seu prestígio aos seus próprios olhos ou ao dos outros ao aceitar materiais, símbolos e insígnias de outros grupos como se um poder mágico pudesse passar por imitação; [...] De fato, seria difícil selecionar qualquer cultura ou subgrupo cujos símbolos culturais fossem totalmente de sua própria criação ou de sua própria história. Além disso, tais identidades "emprestadas" são freqüentemente úteis ou funcionais num mundo onde velhos grupos são degradados ou novas categorias e etnicidades estão sendo criadas. (Graburn, 1976a, p. 27, tradução minha). 
Ao tratar dessas identidades, Graburn aponta para a possibilidade de as percebemos em constante mudança em face dos contextos de interação dos grupos sociais no cenário mundial. E é justamente ao abordar a mudança cultural que os temas da etnicidade, da identidade ou, em suma, do turismo étnico entram em cena ao se privilegiar uma análise da dinâmica em que os grupos se renovam objetivando a interação com o turismo. Mas trata-se de formas de etnicidade não generalizáveis a todos os contextos interétnicos, dada sua necessidade de envolvimento específico com sistemas globais (e fluxos culturais transnacionais).

De forma resumida, MacCannell (1992c) usa o termo "etnicidade construída" com referência às várias identidades étnicas que emergiram por meio de oposição às colonizações. Mas "etnicidade construída" seria apenas um "trampolim conceitual para um fenômeno mais complexo":

A difusão global da cultura branca, colonização interna e as instituições do moderno turismo de massa estão produzindo novas e mais formas étnicas altamente determinísticas do que aquelas produzidas durante a primeira fase colonial. O foco está num tipo de etnicidadepara-turismo no qual culturas exóticas figuram como atrações chave: onde os turistas vão ver costumes folk no uso diário, loja para artefatos folk em bazares autênticos, ficar alerta para forma de nariz, lábios, seios e assim por diante, aprender algumas normas locais para comportamento, e talvez aprender algo da linguagem... Os esforços aqui não são com os resultados freqüentemente bizarros dos esforços dos turistas para "fazer-se-nativo". Antes, são com os esforços dos nativos para satisfazerem a demanda turística, ou para "fazer-senativo-para-turistas”. (MacCannell,1992c, p. 158-159, tradução minha).

Em termos metodológicos haveria também um redirecionamento para a abordagem dessas novas formas de etnicidade na medida em que, ao contrário das interações típicas do colonialismo clássico, o turismo promove a restauração, preservação e recriação de atributos étnicos. Assim, essa "etnicidade reconstruída" (essas identidades turísticas que emergem em resposta às pressões da "cultura branca" e do turismo) se resume na manutenção e preservação de elementos étnicos para persuasão ou divertimento, não de outros específicos como no caso da etnicidade construída, mas de um "outro generalizado". Mesmo que dependentes dos estágios anteriores 
de etnicidade, as formas étnicas reconstruídas estão aparecendo como resultados mais ou menos automáticos de todos os grupos no mundo que entram numa rede de relações globais de transações comerciais. Dessa forma, os itens de cultura podem ser ressignificados como mercadorias, além de servirem de armamento retórico, isto é, como forma de expressão simbólica com um propósito ou um valor de troca num sistema maior (MacCannell, 1992c, p. 168).

Em tal contexto, ganha expressão o rótulo de turismo étnico. Van den Berghe e Keyes (1984) lembram que

parte do exotismo buscado pelas crescentes hordas de turistas é inerente à fronteira étnica que separa o turista do nativo. Turismo necessariamente envolve contato com nativos através de uma barreira cultural. Isso é verdade mesmo em situações onde o turista não busca ativamente exotismo étnico, e está primariamente interessado em paisagens, monumentos... (van den Berghe; Keyes, 1984, p. 345, tradução minha).

Porém, quando o "exotismo étnico ${ }^{2}$ é buscado, então uma forma distinta de turismo pode ser identificada - 'turismo étnico'. No turismo étnico, o nativo não está simplesmente 'lá' para servir as necessidades do turista; ele está ele mesmo 'em exposição', um espetáculo vivo a ser escrutado, fotografado..." (van den Berghe; Keyes, 1984, p. 345, tradução minha). Para os autores, entretanto, a questão da autenticidade deve ser reforçada no turismo étnico, pois a própria "busca pelo exótico está se autodestruindo por causa da influência esmagadora do observador sobre o observado" (van den Berghe; Keyes, 1984, p. 345, tradução minha). O turista não quer ver o que eles chamam de tourees, isto é, um ator que modifica seu comportamento para lucrar de acordo com essa percepção de que é atrativo para o turista. O turista quer ver "nativos intactos", mas sua própria presença mudaria os nativos ao torná-los menos exóticos e "tradicionais" (mais parecidos com o próprio turista) e ao incentivar que eles transformem-se em tourees. Estes, na medida em que respondem ao turista, fazem dele seu

2 Para os autores, a mercadoria básica do turismo é o exotismo, o que é verdade também para o turismo étnico, o qual, entretanto, carregaria com ele o problema especial da autenticidade.

O turista não-étnico não se preocuparia se um determinado vulcão seria autêntico. 
negócio ao preservar uma ilusão acreditável de autenticidade. O touree "falsifica sua arte, sua roupa, sua música, sua dança, sua religião, e assim por diante, para satisfazer a sede do turista étnico por autenticidade ao mesmo tempo em que a invasão turística assalta sua cultura e sujeita-a ao processo homogeneizante conhecido como "modernização"' (van den Berghe; Keyes, 1984, p. 346, tradução minha). Assim, a procura turística por autenticidade estaria condenada pela própria presença dos turistas e, para o turista étnico, o turismo destrói a própria coisa que ele procura ver: o nativo intacto.

No turismo étnico teríamos então o seguinte:

o touree é o nativo quando ele começa a interagir com o turista e modificar seu comportamento conformemente. O touree é o nativo que virou ator, quer consciente ou inconscientemente - enquanto o turista é o espectador. O intermediário é o mediador no exotismo étnico que media e lucra pela interação de turista e touree, e quem, no processo, muito freqüentemente manipula a etnicidade para ganhar, organiza "autenticidade", distribui valores culturais, e assim torna-se um agente ativo ao modificar a situação na qual e da qual ele vive. (van den Berghe; Keyes, 1984, p. 347, tradução minha).

Pode-se perceber, por tudo isso, o quanto o turismo étnico se distancia do turismo cultural, que pode ser definido "em termos de situações onde o papel da cultura é contextual, onde seu papel está para moldar a experiência do turista de uma situação em geral, sem um foco particular sobre a singularidade de uma identidade cultural específica" (Wood, 1984, p. 361, tradução minha), ou seja, sem o engajamento de grupos étnicos que buscam produzir uma identidade a ser comprada pelos turistas.

O turismo étnico teria ainda sua principal ocorrência entre os povos do Quarto Mundo33, em "regiões de refúgio" (Béltran, 1979 apud. van den Berghe, 1994) agora invadidas por turistas que buscam redescobrir nativos para além das fronteiras do capitalismo global ou do colonialismo - o que

${ }^{3}$ Quarto Mundo é um "nome coletivo para todos povos aborígines ou nativos cujas terras ficam dentro de fronteiras nacionais e administrações tecnoburocráticas dos países do Primeiro, Segundo e Terceiro Mundos. Como tais, são populações sem países próprios, que estão geralmente em minoria e sem o poder de dirigir o curso de suas vidas coletivas" (Graburn, 1976 b, p. 1, tradução minha). 
não quer dizer que o turismo não se apresente, assim, como uma nova versão de colonialismo (Grünewald, 2002a). Aí se torna relevante pensar no valor da cultura para este tipo de turismo na medida em que ela parece se valorizar pela distância cultural do viajante - o que não quer dizer que essa mesma cultura seja o centro da etnicidade nativa, que os nativos estejam interessados em forjar uma etnicidade para turista e que o turismo étnico seja, de fato, uma opção vantajosa em todos os casos.

MacCannell sustenta que turismo étnico segue "caminhos estruturais existentes" (MacCannell,1992d, p. 174) e nem sempre vantajosos para os nativos, pois na maioria das vezes a estrutura do turismo étnico acaba por favorecer o gasto de dinheiro com câmeras, filmes, etc. - e isso mesmo se a atração étnica é o motivo único de uma viagem. Isso reforça sua suposição de que "os tipos de mudanças que são necessárias para desenvolver uma comunidade para turismo étnico raramente melhora as vidas de seus membros, como algumas vezes ocorrem no desenvolvimento para outras formas de turismo" (MacCannell, 1992d, p. 175, tradução minha). Para este autor:

turismo étnico é especialmente vulnerável a uma forma de desordem social. Grupos étnicos turistificados são freqüentemente enfraquecidos por uma história de exploração [...], limitados em recursos e poder, e eles não têm grandes prédios, máquinas, monumentos ou maravilhas naturais para desviar a atenção dos turistas para longe dos detalhes íntimos de suas vidas diárias. (MacCannell, 1992d, p. 175-176, tradução minha).

É assim que Nagel (1996) mostra que muitos índios norte-americanos não têm interesse em interagir com os turistas e então, ao invés de promover o turismo étnico, recorrem ao da jogatina (cassinos) - o que só vem a corroborar a idéia de que o turismo étnico é opção também a partir do nativo e não se estabelece somente através do olhar do visitante.

Mas o que dizer com relação especificamente aos nativos dessas aldeias turísticas? MacCannell também sugere que as atrações étnicas realçam a importância de uma autoconsciência e autodeterminação emergentes da "minoria" étnica, a necessidade de corrigir o registro histórico: trata-se de lembrar aos visitantes a discriminação passada contra a "minoria". Apesar disto, o autor sustenta que nos contextos de turismo étnico somente a retórica das relações étnicas muda para criar a impressão de progresso, enquanto 
formas mais velhas de repressão e exploração são perpetuadas debaixo da superfície. Para ele, é assim que a pseudomudança funciona, pois quando um grupo étnico começa a se vender, ou é forçado a se vender, ou é vendido como uma atração étnica, ele cessa de se desenvolver naturalmente e os membros do grupo começam a se pensar "não como um povo mas como representantes de um autêntico modo de vida. Repentinamente, qualquer mudança no estilo de vida não é mera questão de utilidade prática, mas um assunto pesado que tem implicações econômicas e políticas para o grupo inteiro" (MacCannell, 1992d, p. 178, tradução minha).

Mas há ainda outras questões que poderiam ser esmiuçadas ao se tratar da produção de turismos étnicos ou mesmo do amplo tema do turismo e etnicidade. Wood (1997) já ressaltou que existem muitas instituições mediando os relacionamentos entre turismo e etnicidade, mas o Estado seria a maior dessas instâncias. Nagel (1996) ressalta que, em sendo o Estado uma instituição dominante na regulação de etnicidades, é importante não perder de vista a construção política da etnicidade através principalmente dos caminhos das designações étnicas oficiais, através da distribuição de recursos a através de regras e estruturas de acesso político.

Picard e Wood (1997) têm mostrado instâncias nas quais turismo pode ajudar objetivos de Estados-Nações em seus relacionamentos com minorias étnicas dentro de suas fronteiras, pois turismo tem, inclusive, e entre outras possibilidades demonstradas na coletânea deles, promovido oportunidades para representações das construções culturais de minorias étnicas que são compatíveis com a ideologia nacional. De forma semelhante, Jamison (1999) aponta como turismo pode atenuar conflitos em comunidades multiétnicas.

Por fim, Chambers (2000) mostra que o rótulo turismo étnico tem sido usado para se referir a atividades que engajam os turistas na experiência de eventos e situações culturais que são distintas da sua própria. Através de alguns exemplos ressalta como turismo focalizado sobre base da etnicidade provê interessantes exemplos de como diferentes indicadores e símbolos de status étnico podem ser negociados.

De uma maneira geral, penso que o turismo étnico pode ser percebido sob duas perspectivas: uma voltando-se para o que se busca no turismo, e, no caso, o nativo seria o foco da viagem (visitação). Mas outra perspectiva seria ver o turismo étnico pelo que o turista vê (encontra) durante a visitação. Talvez se possa contra-argumentar dizendo que toda visitação a outra nação já admitiria o fato do turismo étnico. Mas o que deve estar para defini-lo é o movimento de construir uma etnicidade específica para exibição na arena turística. A idéia de turismo, inclusive, parece recair sobre a 
perspectiva daqueles que viajam. Se o ângulo for mudado e se perceber sob o olhar do nativo, é justamente a etnicidade acionada em termos de produção cultural de tradições a serem exibidas com sinais diacríticos em arenas turísticas que vai ressaltar o caráter étnico destas - e mesmo que isso ocorra sem plena compreensão do processo pelos nativos e, conseqüentemente, sem um planejamento para o desenvolvimento dos fluxos turísticos para suas aldeias.

Mas vista a amplitude de grupos que podem ser considerados étnicos (que se apresentam assim, inclusive), talvez possamos buscar uma maior problematização de possíveis distinções que se possam tentar estabelecer entre as comunidades étnicas e aquelas criadas para turismo, e de como podem se entrelaçar concreta (empírica) e teoricamente. Não estou aqui preocupado apenas com a sobreposição do turismo étnico e do que recai sobre legado cultural (Barretto, 2002) para identificar melhor suas fronteiras ou sua participação simultânea nos mais variados contextos turísticos, mas preocupado com uma maior precisão semântica de algumas concepções sobre turismo étnico, pois sou favorável, antes de tudo, ao posicionamento de que o fato de ser nativo turístico e se vender na arena turística não caracteriza falta de autenticidade - e devia-se indagar: autenticidade aos olhos de quem? Mas vale elaborar algumas questões: a etnicidade voltada para turismo é etnicidade ou essa revisão cultural deve ser separada da etnicidade? Ser um povo para outro é uma forma de ser para si (em si)? São etnicidades o que as comunidades (étnicas) acionam em arenas turísticas, ou há uma formação de comunidades etnoturísticas que fomentam uma etnicidade turística essencialmente "falsa" (Wood, 1997)? O turismo deve ver com legitimidade essa forma moderna de etnicidade comercial criada para turistas (afinal é uma demanda criada pelo próprio fenômeno do turismo)? E quanto aos lugares do turismo étnico, como distinguir o que é próprio da etnia e o que é elaborado para o turismo? Cabe essa distinção?

\section{Comunidades étnicas e comunidades turisticas}

MacCannell sustenta que o "moderno turismo de massa está baseado em duas tendências aparentemente contraditórias: a homogeneização internacional da cultura dos turistas e a preservação artificial de grupos étnicos locais e atrações tais que elas possam ser consumidas como experiências turísticas" (MacCannell, 1992d, p. 176, tradução minha). Elege, aí, a idéia de 
um terreno de encontros vazios para salientar o lugar de visitação, onde as pessoas vivem e os turistas visitam, um lugar que tem sido decorado para parecer uma cidade ideal de algum tipo. E o que se testemunharia em aldeias que foram transformadas por turistas é "a reificação das virtudes sociais simples, ou o ideal da 'vida aldeã', para 'alguém ver"'. A aldeia não é destruída, mas sua função primária muda e não se funda mais sobre relacionamentos humanos, mas torna-se um detalhe nas experiências recreacionais de um turista de fora da cidade. Ironicamente, para ele, "o turista está freqüentemente buscando experimentar um lugar onde relacionamentos humanos ainda parecem existir"; esse processo seria "tão avançado" que não apenas estaria afetando comunidades reais, mas "produzindo pseudocomunidades para atenção turística” (MacCannell, 1992d, p. 176, tradução minha). Acredito que aqui deva se deslocar o foco da idéia de "pseudocomunidades" para uma idéia de comunidades turísticas, que podem se sobrepor às comunidades étnicas num mesmo espaço social e territorial.

Para se pensar as comunidades étnicas, acredito que o melhor é retomar a clássica posição de Weber (1991), para quem a comunidade deve ser apreendida enquanto sentida subjetivamente pelos seus membros como uma marca característica comum e enquanto dispensando, dado às crenças subjetivas - como a crença no parentesco de origem - daí decorrentes, o estabelecimento de fronteiras bem delimitadas. Isso está em consonância tanto com o trabalho de Barth (1969) quanto com o de Gluckman (1987), para quem, segundo afirmou Oliveira (1988), a noção de comunidade "não supõe limites espaciais bem delimitados, nem unidades em termos de código de orientação cultural, mas somente que sejam partilhados determinados padrões de interação no comportamento cotidiano dos indivíduos uns para os outros" (Oliveira, 1988, p. 39).

Nesse momento em que o foco da investigação torna-se, de fato, a "fronteira étnica que define o grupo" e não a "substância cultural que ela encerra" (Barth, 1969) é que se deve olhar para o grupo étnico como uma forma de organização social, onde interessa menos o traço cultural atribuído do que a própria característica de auto-atribuição e atribuição por outros: a atenção recai sobre um conjunto de membros que se identifica e é identificado por outros como uma população distinta. Ainda no que concerne às relações interétnicas, gostaria de ressaltar que não apenas a interação é, em si, um fator gerador de cultura e de limites para cada grupo, como os contatos 
externos a um grupo são também constitutivos da estrutura desse grupo. Mas a comunidade é também uma construção simbólica. Para Cohen (1985):

cultura - a comunidade como experimentada por seus membros não consiste em estrutura social ou "no fazer" do comportamento social. Ela é inerente "no pensar" sobre ela. É nesse sentido que podemos falar de comunidade como um construto simbólico antes que estrutural. Ao se procurar compreender o fenômeno da comunidade, nós temos que considerar suas relações sociais constituintes como repositórios de significado para seus membros, não como um conjunto de elos mecânicos. (Cohen, 1985, p. 98, tradução minha).

De outro ponto, Bourdieu (1989b) percebe, com relação aos grupos étnicos e sua formação, que os agentes e grupos de agentes são definidos por suas posições relativas no "espaço social". A partir de um tal quadro, o objeto do pesquisador deve ser a disputa pelo privilégio de impor uma visão das coisas, pois a luta pela imposição de uma visão legítima do mundo (onde se encaixam as lutas a respeito da identidade étnica) é o próprio âmbito da etnicidade (ou é a própria etnicidade) — e é assim que se dá a institucionalização de um grupo étnico, ou seja, pelas "lutas pelo monopólio de fazer ver e fazer crer, de dar a conhecer e de fazer reconhecer, de impor a definição legítima das divisões do mundo social e, por este meio, de fazer e de desfazer os grupos" (Bourdieu, 1989a, p. 113). Assim, deve-se evitar uma percepção naturalizada das fronteiras de um grupo étnico, uma vez que essas passaram por um processo político de legitimação, quando o grupo passou a ter sua existência conhecida e reconhecida num amplo cenário social.

Mas o ponto a que quero chegar é que me parece que, mesmo quando uma etnicidade se alavanca em face do turismo, isso não quer dizer que os limites da comunidade étnica sejam coincidentes com os da arena turística (ou seja, o espaço social onde ocorrem interações geradas pela atividade turística), onde atores nativos constroem uma encenação de si, e com a qual se identificam de fato, e se formando como uma comunidade, a que chamo de turística. Ou seja, nem todos os nativos da comunidade étnica estão engajados na etnicidade para o turismo, mas os que estão acabam por formar uma outra comunidade, a turística, que, por se constituir e se apresentar por linhas étnicas, pode ser chamada de comunidade etnoturística. 
Há etnicidade aí e a identidade étnica construída nesse palco também é legítima e autêntica na medida em que autênticos e legítimos são os turismos nesses espaços sociais. Esse é o mais próprio turismo étnico, pois querer sair da fachada e penetrar nas profundezas da vida nativa é coisa para antropó$\operatorname{logo}$, e não para turista.

Além disso, as arenas turísticas podem ser muito bem aproveitadas para o posicionamento (discursivo) das comunidades étnicas no mundo globalizado. Essas comunidades acabam muitas vezes por fazer dessas arenas os pontos de onde conseguem falar de si ao mundo, um mundo pós-moderno que necessita cada vez mais do primitivo como contraponto estratégico.

Mas, e quanto então ao ingresso dos nativos, em termos de sua "aculturação"/etnicidade, nas arenas em foco? Acredito que os turistas devam saber de antemão que vão se deparar na aldeia com aquilo que temos chamado de touree e que MacCannell (1992a) chamou de "ex-primitivos", os quais podem ser pensados a partir de duas entradas: "povos recentemente aculturados perdidos no mundo industrial, e um outro tipo de ex-primitivo, ainda sob o rótulo de 'primitivo', um tipo de 'primitivo performativo", (MacCannell, 1992a, p. 26, tradução minha). Trata-se de um espaço criado no mundo pós-moderno, que permite aos índios "aculturados" evitarem o trabalho cotidiano em fábricas ou fazendas a partir da "institucionalização de performances de primitivos para outros" - o que se manifesta "como uma simples forma cultural híbrida" (MacCannell, 1992a, p. 19, tradução minha). O termo "primitivo", para este autor, seria assim apenas uma crescente resposta a uma "necessidade mítica" para manter a idéia do primitivo viva no mundo e na consciência modernos - e ela permaneceria viva porque existem vários impérios constituídos sobre a necessidade do "primitivo". A pós-modernização se basearia assim em um princípio oposto àquele da assimilação, uma vez que "povos tradicionais, incluindo ex-primitivos, especialmente aqueles que têm adotado o turismo como seu meio de ganhar a vida, agora têm a opção de basear seu avanço econômico no fazer um show de suas qualidades distintivas, sua singularidade cultural" (MacCannell, 1992b, p. 101, tradução minha).

\footnotetext{
4 Para MacCannell, “a performance 'primitivística' contém a imagem do primitivo como uma forma morta", e "a imagem do selvagem que emerge dessas performances ex-primitivas completa a fantasia pós-moderna de 'alteridade autêntica' que é ideologicamente necessária na promoção e desenvolvimento da monocultura global" (MacCannell, 1992a, p. 19, tradução minha).
} 
Acredito, assim, que os membros de comunidades étnicas podem se inserir em atividades turísticas, formando, junto com outros membros da comunidade étnica e outros que não o são, comunidades turísticas, que existem concretamente e cujas fronteiras podem ser bem mais amplas tanto do que as da arena turística onde se desenvolve a experiência turística quanto do que a da comunidade étnica. Mas se há uma etnicidade que é elaborada nessa arena e visando os recursos turísticos, há então uma experiência de turismo étnico. Os membros da comunidade étnica envolvidos nesse processo e mais todos aqueles de fora da comunidade, mas que também estão envolvidos nessa promoção do turismo étnico, formam todos a comunidade etnoturística. Todas essas esferas são autênticas e legítimas em suas especificidades. Acredito ainda que a recorrência de menções a termos como ilusório, virtual, falso, inautêntico, pseudo, simulacro, etc. para referência às experiências etnoturísticas nessas arenas são inadequadas e emperram a concentração de esforços intelectuais para aquilo que deve prevalecer: a atenção sobre a prática turística desenvolvida com a cumplicidade entre atores e platéia. Estamos diante de três esferas que se sobrepõem e inter-relacionam necessariamente num mesmo espaço social, aqui chamado de arena turística. Por fim, em termos metodológicos, acredito que o foco das pesquisas pode recair sobre quaisquer dessas quatro esferas (as três comunidades ou a arena), vistas como experiências concretas, exemplos de atividade humana com tendências e contribuições específicas, e não rechaçadas ao hall das coisas impuras, poluídas.

\section{Referências}

BANDUCCI Jr., Álvaro; BARRETTO, Margarita. Introdução. In: BANDUCCI Jr., A.; BARRETO, M. Turismo e identidade local: uma visão antropológica. Campinas: Papirus, 2001. p. 7-20.

BARRETTO, Margarita. Turismo e legado cultural. Campinas: Papirus, 2002.

BARTH, Fredrik. Introduction. In: BARTH, Fredrik. Ethnic Groups and Boundaries. London: George Allen and Unwin, 1969, p. 9-38.

BOORSTIN, Daniel. The image: a guide to pseudo-events in America. New York: Harper, 1964. 
BOURDIEU, Pierre. A identidade e a representação: elementos para uma reflexão crítica sobre a idéia de região. In: $O$ poder simbólico. Lisboa: Difel, 1989a. p. 107-132.

BOURDIEU, Pierre. Espaço social e génese de "classes". In: O poder simbólico. Lisboa: Difel, 1989b. p. 133-161.

CHAMBERS, Erve. Introduction: tourism's mediators. In: CHAMBERS, Erve (Ed.). Tourism and culture: an applied perspective. New York: SUNY, 1997.

CHAMBERS, Erve. Native tours: the anthropology of travel and tourism. Illinois: Waveland Press, 2000.

COHEN, Anthony P. The symbolic construction of community. London: Routledge, 1985.

GLUCKMAN, Max. Análise de uma situação social na Zululândia moderna. In: FELDMAN-BIANCO, Bela. Antropologia das sociedades contemporâneas. São Paulo: Global, 1987. p. 227-344.

GRABURN, Nelson H. H. Ethnic and tourist arts: cultural expressions from the Fourth World. Berkeley: University of California Press, 1976a.

GRABURN, Nelson H. H. Introduction: the arts of the Fourth World. In: GRABURN, Nelson H. H. Ethnic and tourist arts: cultural expressions from the Fourth World. Berkeley: University of California Press, 1976b. p. 1-32.

GRÜNEWALD, Rodrigo de Azeredo. Os índios do Descobrimento: tradição e turismo. Rio de Janeiro: Contra Capa, 2001.

GRÜNEWALD, Rodrigo de Azeredo. Os Pataxó e os fluxos coloniais. In: ENCONTRO ANUAL DA ANPOCS, 26., 2002, Caxambu. 2002a.

GRÜNEWALD, Rodrigo de Azeredo. Tourism and cultural revival. Annals of Tourism Research, v. 29, p. 1004-1021, 2002b.

HALL, Stuart. The local and the global: globalization and ethnicity. In: KING, Anthony. Culture, globalization and the world-system. New York: Macmillan, 1991a. p. 19-39.

HALL, Stuart. Old and new identities, old and new ethnicities. In: KING, Anthony. Culture, globalization and the world-system. New York: Macmillan, 1991b. p. 41-68.

JAMISON, David. Tourism and ethnicity: the brotherland of coconuts. Annals of Tourism Research, v. 26, p. 944-967, 1999. 
MacCANNELL, Dean. Cannibalism today. In: MacCANNEL, Dean. Empty meeting grounds. London: Routledge, 1992a. p. 17-73.

MacCANNELL, Dean. Postmodern community planning: notes on the homeless and other nomads. In: MacCANNEL, Dean. Empty meeting grounds. London: Routledge, 1992b. p. 87-113.

MacCANNELL, Dean. Reconstructed ethnicity: tourism and cultural identity in Third World communities. In: MacCANNEL, Dean. Empty meeting grounds. London: Routledge, 1992c. p. 158-171.

MacCANNELL, Dean. The Locke case. In: MacCANNEL, Dean. Empty meeting grounds. London: Routledge, 1992d. p. 172-180.

MURDOCK, G. et al. Outline of cultural materials. New Haven: Human Relations Area Files, 1982.

NAGEL, Joane. American Indian ethnic renewal: red power and the resurgence of identity and culture. Oxford: Oxford University Press, 1996. NASH, Dennison. Anthropology of tourism. Kidlington: Pergamon, 1996. OLIVEIRA, João Pacheco de. "O nosso governo": os Ticuna e o regime tutelar. São Paulo: Marco Zero: CNPq, 1988.

PICARD, Michel; WOOD, Robert E. (Org.). Tourism, ethnicity, and the State in Asian and Pacific societies. Honolulu: University of Hawai'i Press, 1997.

PI-SUNYER, Oriol. Changing perceptions of tourism and tourists in a Catalan resort town. In: SMITH, Valene. Hosts and guests: the Anthropology of tourism. Philadelphia: University of Pennsylvania Press, 1989. p. 187-199.

RYAN, Chris. Tourism and cultural proximity: examples from New Zealand. Annals of Tourism Research, v. 29, p. 952-971, 2002.

SMITH, Valene L. Introduction. In: Hosts and guests: the Anthropology of tourism. Philadelphia: University of Pennsylvania Press, 1989. p. 1-17.

SOFIELD, Trevor H. B. Empowerment for sustainable tourism development. New York: Pergamon, 2003.

STEIL, Carlos Alberto. O turismo como objeto de estudos no campo das ciências sociais. In: RIEDL, Mário; ALMEIDA, Joaquim A.; VIANA, Andyara L. B. Turismo rural: tendências e sustentabilidade. Santa Cruz do Sul: EDUNISC, 2002. 
VAN DEN BERGHE, Pierre L. The quest for the other: ethnic tourism in San Cristóbal, Mexico. Seattle: University of Washington Press, 1994.

VAN DEN BERGHE, Pierre L.; KEYES, Charles F. Introduction: tourism and re-created ethnicity. Annals of Tourism Research, v. 11, p. 343-352, 1984. WEBER, Max. Relações comunitárias étnicas. In: ECONOMIA e Sociedade. Brasília: UnB, 1991. v. 1, p. 267-277.

WOOD, Robert E. Ethnic tourism, the State, and cultural change in Southeast Asia. In: Annals of Tourism Research, v. 11, p. 353-374, 1984. WOOD, Robert E. Tourism and the State: ethnic options and constructions of otherness. In: PICARD, Michel; WOOD, Robert E. (Org.). Tourism, ethnicity, and the State in Asian and Pacific societies. Honolulu: University of Hawai'i Press, 1997.

Recebido em 29/07/2003

Aprovado em 20/08/2003 